\title{
Talqin Dzikir Sebagai Metode Dakwah Jama’ah Dan Fardiyyah
}

\author{
Danial Luthfi* \\ UIN Sunan Gunung Djati Bandung, Indonesia \\ Email: DAL1996@gmail.com
}

\begin{abstract}
The development of the propaganda method is ideally able to keep pace with the times. Today when da'wah is dealing with the conditions of modern society, da'wah is required to use methods that are relevant to the characteristics of modern society. Modern societies that experience the emptiness and dryness of spirituality, coupled with a fast-paced lifestyle, are confronted with their limited free time. This requires the preacher to be able to choose a method that can answer these conditions. Talqin dhikr is one method of da'wah that can accommodate this need. Apart from the short time, it can also directly penetrate the conscience of the mind that is ditaqin. The purpose of this study is to uncover the concepts and processes of talqin dhikr. After that, want to find out how the efficacy of talqin dhikr in the context of the success of preaching. using a qualitative approach by taking the case study method. Data collection techniques are carried out through observation, interviews, and literature study. The results showed that the talqin of dhikr conceptually and the process was a method of da'wah that could answer the problems of modern society. In addition, both in congregation and individually, the dhikr talqin is able to bring the talqin participants to the touch of the margin aspect of al-thâthifiy (emotional-spiritual); second, the margin of al-qaqliy (rational); and finally margin al-hissiy (sensory).
\end{abstract}

Keywords: Talqin; Da'wah: Method.

\begin{abstract}
Abstrak
Perkembangan metode dakwah idelanya mampu mengimbangi perkembangan zaman. Hari ini ketika dakwah berhadapan dengan kondisi masyarakat modern, dakwah dituntut menggunakan metode yang relevan dengan karakteristik masyarakat modern. Masyarakat modern yang mengalami kehampaan dan kekeringan spiritualitas, ditambah dengan gaya hidup yang serbacepat, berhadapan dengan luangnya waktu mereka yang serba terbatas. Hal ini menuntut da'i mampu memilih metode yang bisa menjawab kondisi tersebut. Talqin dzikir adalah salah satu metode dakwah yang bisa mengakomodir kebutuhan ini. Selain karena waktunya yang singkat, juga bisa langsung menembus kesadaran batin yang ditaqin.Tujuan penelitian ini adalah untuk mengungkap konsep dan proses talqin dzikir. Setelah itu, ingin mengetahui bagaimana keampuhan talqin dzikir dalam konteks keberhasilan dakwah. menggunakan pendekatan kualitatif dengan mengambil metode studi kasus. Teknik pengumpulan datanya dilakukan melalui observasi, wawancara, dan studi pustaka. Hasil penelitian menunjukkan, bahwa talqin dzikir secara konseptual dan prosesnya merupakan metoda dakwah yang bisa menjawab problematika masyarakat modern. Selain itu, baik secara berjamaah maupun individual, talqin dzikir mampu mengantarkan peserta talqin pada tersentuhnya aspek margin al-'âthifiy (emosionalspiritual); kedua, margin al- 'aqliy (rasional); dan terakhir margin al-hissiy (inderawi).
\end{abstract}

Kata Kunci: Talqin; Dakwah : Metode.

\section{PENDAHULUAN}

Islam sejak awal tegas menyatakan bahwa dakwah adalah salah satu perangkat untuk mengantarkan manusia pada kehidupan yang mulia. Kemuliaan manusia tersebut, berdiri di atas dua hal, pengetahuan (al-ilm) dan karya nyata (al-'amal). Keduanya memiliki posisi penting secara bersamaan, 
Khazanah Theologia, Vol. 1 No. 1: 1-6

Talqin Dzikir Sebagai Metode Dakwah Jama'ah Dan Fardiyyah Danial Luthfi

tidak sempurna jika yang satu mengabaikan yang lainnya, ibarat dua sisi mata uang yang tidak bisa dipisahkan (Umar, 2004).

Pengetahuan dalam keseluruhan maknanya, dan karya nyata dengan berbagai bentuknya, dalam Islam terikat dengan dua sumbu keluhuran. Pertama, sumbu vertikal berupa tanggung jawab yang bersifat teosentris, kepada dzat causa prima Allah SWT. Atau (habl min al-lâh). Kedua, tanggung jawab sosial horizontal yang bersifat antroposenris kepada sesama manusia dan semesta lingkungan tempat di mana manusia tinggal (habl min al-nâs).

Posisi dakwah dalam Islam tidak hanya fasilitasi pecapaian kemuliaan hidup manusia. Namun dakwah juga berperan untuk memastikan dan mengawal, bahwa antara ilmu dan amal, selain selalu bejalan beriringan, juga tetap pada alur dan jalur (on the track) yang dikehendaki Allah SWT. (sabîli rabbika).

Tidak bisa dipungkiri bahwa, ilmu pengetahuan dan karya nyata manusia, pada gilirannya banyak yang bergerak keluar dari fitrahnya. Akibatnya, meskipun pengetahuan terus berkembang teknologi sebagai hasil karya manusia semakin tinggi, tetapi pada saat yang bersamaan kerusakan sumber daya manusia dan alam semesta, jelas terlihat di depan mata.

Pada kulminasi tertentu, ilmu dan karya manusia mengalami kondisi yang bernama kehampaan spiritualitas. Ilmu pengetahuan dipuja sedemikian rupa, namun tidak bisa memuaskan dahaga jiwanya. Hasil karya berupa teknologi canggih dipuji setinggi langit, tetapi tidak bisa menyelesaikan kekeringan bathinnya.

Jika kondisi ini dibiarkan maka akan banyak hal yang kontraproduktif dilakukan manusia. Dengan ilmu pengetahuan dn keyakinannya manusia bisa saling mengkafirsesatkan bahkan saling menumpahkan darah. Padahal idealnya semakin tinggi pengetahuan mestinya semakin arif dan bijaksana. Dengan kemampuan menguasai teknologi hasil karya tangannya, manusia bisa pamer kedigjayaan, bahkan saling menikam dan menjajah satu dengan yang lainnya. Padahal seyogianya mereka bisa saling membedayakan dan mensejahterakan.

Dengan kondisi seperti inilah dakwah, sekali lagi, harus memastikan dan mengawal ilmu dan amal manusia tetap pada fitrahnya. Bukan hanya retorika yang menampilkan dialektik-akrobatik dan bukan hanya dagelan perbuatan yang tidak bernilai paripurna. Namun dakwah yang membangunkan kesadaran bathiniyahnya, menyapa kesadaran puncak ruhaninya, membangkitkan ketenangan jiwanya, dan menggugah ketersambungan spiritulitasnya dengan Allah SWT (Sukayat, 2009).

Tugas dakwah tugas memang berat tetapi mulia. Disebut berat karena pada hakikatnya dakwah adalah upaya menggerakan manusia ke arah hidayah dan kebaikan, melalui al-amr bi al-marûfdan al-nahy 'an al-munkar, agar manusia bertemu dengan kebahagiaan dunia dan akhirat. Dan terutama, tugas dakwah adalah misi utama para nabi dan rasul, yang menjadi amal yang terbaik setelah beribadah kepada Allah. Sedangkan disebut mulia karena dakwah adalah satu-satunya upaya terbaik, yang menurut Al-'Adnâniy, mendapat pengakuan Allah dalam al-Quran, tidak digunakan untuk aktivitas lain, seperti shalat dan yang lainnya ${ }^{1}$.

Tugas dakwah tersebut melekat pada pribadi seorang Muslim. Kapan saja dan di mana saja, di pundak seorang Muslim terdapat beban tanggung jawab dakwah. Bahkan, setelah menjalani profesi apapun dalam kehidupannya, seorang Muslim masih berkewajiban untuk menyampaikan dakwah. Karena hal inilah, wajar jika ada pernyataan yang menyebutkan nahnu du'ât qabla kulli syaiin; kita [umat Islam] adalah juru dakwah sebelum menjalani apapun profesi lainnya.

\footnotetext{
${ }^{1}$ Ahmad bin Muhammad al-Dasam al-'Adnâniy, Al-Da 'wah al-Islâmiyyah li al-Afrâd wa al-Syabâb, (Madînat al-Munwwarat: Dâr al-Zamân, 2008), h. 11
} 
Khazanah Theologia, Vol. 1 No. 1: 1-6

Talqin Dzikir Sebagai Metode Dakwah Jama'ah Dan Fardiyyah Danial Luthfi

Mengingat dakwah adalah pekerjaan yang berat tetapi mulia, maka pada praktiknya, juru dakwah perlu memilih dan menggunakan metode yang tepat. Alasannya, demi keberlangsungan masa depan dan keberhasilan dakwah. Sebagaimana dimaklumi, keberlangsungan dakwah akan terus berkelanjutan, bersamaan dengan berlangsungnya kabaikan yang vis a vis keburukan. Kebaikan di satu sisi adalah misi dakwah islâmiyah, sementara keburukan pada sisi yang lain adalah misi dakwah syaithâniyyah (Hefni, 2006).

Pada hari ini $d a^{\prime i}$ dihadapkan pada situasi objek dakwah ( mad'u $^{\prime}$ yang memiliki waktu yang serba terbatas. Belum lagi, trend kehidupan modern yang menuntut segala hal dengan serba cepat. Karena itu, dibutuhkan metode yang tepat yang bisa memanfaatkan keterbatasan waktu tersebut. Sehingga, meskipun dalam waktu yang cepat, mad'u bisa merasakan manfaat dari dakwah yang disampaikan oleh da'i tadi.

Selain itu, problem utama hari ini, sebagaimana disebutkan di atas, perlu menyentuh aspek esoteris manusia. Perlu membangkitkan bathin manusia. Perlu menmbuhkan kesadaran spiritualitas manusia. Perlu menghidupkan ruhani agar selalu connected (tersambung) kepada Allah SWT. Sehingga, dengan keserbaterbatasan waktu manusia modern, dan keserbacepatan aktivitas mereka, ruhani mereka masih bisa merasakan kemesraan asyik-maksyuk dengan Allah SWT.

Tashawwuf sebagai salah satu disiplin ilmu dalam Islam menawaran metode yang menjawab masalah di atas. Di dalam tashawwuf terdapat madzhab-madzhab atau ordo-ordo yang dikenal dengan thariqat. Dan di dalam thariqat itu sendiri terdapat metode dakwah yang bisa mengakomodir keterbatasan kesempatan sekaligus keserbacepatan masyarakat modern, yaitu metode talqin dzikir.

Talqin di sini bukan dalam makna yang dipahami secara umum. Yaitu berupa kegiatan membisikkan (menyebutkan) kalimat syahadat dekat orang yang hendak meninggal atau dalam bentuk doa untuk mayat yang baru dikuburkan. Akan tetapi, talqin yang dimaksud adalah dalam makna khusus, sebagaimana dimaksud oleh Ibnu Arabi, berupa proses memasukkan nûr nubuwwah oleh seorang mursyid ke dalam hati sâlik (murid) (Alba, 2012).

Memang, jika dilihat secara kasat mata, pada praktiknya, proses talqin berbentuk penyampaian tatacara dzikir kepada sâlik. Namun secara spiritual, talqin merupakan penanaman cahaya iman agar tumbuh subur dan menghasilkan amal shaleh.

Kedua makna talqin tadi, sebenarnya diakomodir dalam pengertian secara etimologis. Karena secara lughawiy, talqin merupakan turunan dari kata laqqana-yulaqqinu-talqînan, yang berarti mengajarkan secara lisan, mendikte, dan membisikkan.

Secara historis, talqin sebenarnya bukan hal yang baru. Bahkan talqin dzikir merupakan metode dakwah yang paling pokok dan paling awal dipilih oleh Nabi Muhammad SAW. Talqin ini dipilih oleh Nabi SAW. Untuk menyampaikan ajaran mendasar dalam Islam kepada para sahabat, baik yang dilakukan secara personal maupun komunal (berjamaah).

Di dalam proses talqin terjadi dialog antara mursyid dengan sâlik. Pada saat proses tersebut berlangsung, sâlik menyampaikan kesanggupan dan kesetiaan kepada mursyid untuk melaksanakan tatacara dzikir sebagaimana yang diajarkan oleh mursyid saat itu. Karena hal inilah, talqin selalu disamakan pengertiannya dengan bay'at.

Pada titik inilah talqin dalam perpektif komunikasi dakwah dapat dikategorikan sebagai metode dakwah, baik secara berjamaah (jamâ'atan) maupun perorangan (fardiyyatan) (Mubârak, 2005) Kedekatan hubungan dialogis yang dipadukan dengan kesadaran untuk setia dan sanggup mengerjakan ajaran Islam, antara sâlik dengan mursyid, akan membentuk awareness by proximity (kesadaran berbasis kedekatan). 
Kedekatan yang melahirkan kesadaran dari proses dialogis antara mursyid dengan sâlik, menimbulkan hubungan emosional yang kohesif. Muzaffer Ozzak, menggambarkan hubungan ini laksana dokter dengan pasiennya. Para sâlik berbondong-bondong datang meminta nasihat, doa, dan membawa berbagai masalah, yang mereka anggap dapat diselesaikan oleh sang mursyid tadi. Melihat betapa strategisnya talqin sebagai metode penyampaian dakwah Islam, penyusun tertarik untuk menelitinya secara intensif dengan judul penelitian Talqin Dzikir Sebagai Metode Dakwah Jama'ah dan Fardiyyah (Studi Kasus Terhadap Metode Talqin dalam TQN PP. Suryalaya di Pesantren Sirnarasa Panjalu Ciamis).

\section{METODE PENELITIAN}

Metode yang digunakan dalam penelitian ini adalah metode studi kasus (Kuswarno, 2009). Studi kasus yang dimaksud, sebagaimana diungkapkan Deddy Mulyana, adalah uraian dan penjelasan komprehensif mengenai berbagai aspek seorang individu, suatu kelompok, suatu organisasi (komunitas), suatu program, atau suatu situasi sosial.

Sebagai metode dari pendekatan penelitian kualitatif, metode ini dipilih karena, sebagaimana dikatakan Bogdan dan Bikien (1982), penelitian ini terfokus pada satu latar atau objek. Tepatnya, penelitian ini terfokus pada proses talqin dzikir sebagai metode dakwah dalam TQN Pondok Pesantren Suryalaya (selanjutnya disebut TQN PP. Suryalaya).

\section{HASIL DAN PEMBAHASAN}

\section{Konsep dan Proses Talqin Dzikir Sebagai Metode Dakwah Jama'ah dan Fardiyyah}

Sebagai metode dakwah, talqin sangat dekat dengan upaya menyentuh margin emosional-spiritual dimana talqin sebangun dengan metode direktif dalam konseling. Pembimbing talqin menjadi konselor dan peserta talqin sebagai klien. Pesan-pesan dakwah disampaikan dalam nuansa concelor-centred (terpusat pada konselor) (Cucu, 2010).

Pesan dakwah yang akan disampaikan kepada mad'u harus disesuaikan dengan kerangka referensi (frame of reference), maksudnya adalah bahwa ketika akan memberikan pesan harus memperhatikan siapa yang menjadi audiens, sehingga mereka mereka dapat memahami apa yang kita sampaikan. Berbeda dengan talqin, karena talqin diberikan oleh guru murysid atau para wakil talqin, dan hanya dengan materi talqin yang sudah ditentukan pertimbangan secara langsung mengenai siapa murid yang akan ditalqin bukan menjadi hal utama karena isi talqin merupakan inti dari kebutuhan jiwa murid dalam kondisi apapun (Alba, 2012).

Secara konseptual talqin dzikir dilaksanakan secara formal atau kasat mata, talqin dzikir adalah petunjuk dan penjelasan tentang kaifiyat dzikir jahr dan dzikir kahfiy, yang disampaikan oleh mursyid sebagai pemegang otoritas talqin, atau yang diberi wewenang untuk menyampaikan talqin tersebut atas nama mursyid, yang disebut wakil talqin. Secara substansial talqin dzikir bermakna menanamkan kalimat talqin lâ ilâha illâ al-lâh, ke dalam ruh peserta talqin oleh guru mursyid. Di dalam mentalqin dzikir, seorang guru mursyid dapat melakukan kepada jama'ah (banyak orang) atau kepada perorangan sebagaimana Rasulullah SAW. telah mentalqin para sahabatnya, baik secara berjama'ah atau perorangan.

Sedangkan yang dimaksudkan Komunikasi yang kita lakukan tidak akan efektif apabila komunikan sedang marah, sedih, bingung, lapar, sakit, dan lain sebagainya.

Prosesnya terbagi menjadi tiga tahap. Pertama, peserta talqin dalam kondisi sangat siap menerima informasi, arahan, dan bimbingan atau berada dalam kondisi state of personality, yaitu keadaan fisik dan psikis murid pada saat ia menerima proses talqin. Karena talqin terjadi atas permintaan dan/atau 
kesediaan peserta talqin. Artinya, jika tidak meminta ditalqin, maka peserta talqin bersedia ditalqin ketika ditawari. Kedua, posisi pembimbing talqin yang sangat dominan. Dominasi ini dapat dimanfaatkan sebagai ruang menyapaikan pesan dakwah, yang pada bentuk dan metode dakwah lain, perlu energi lebih besar. Ketiga, tahap evaluasi talqin dzikir.

Adapun pelaksanaannya, proses talqin dzikir ada dua macam dzikir, yaitu dzikir jahr yaitu mengucapkan kalimat thayyibat lâ ilâha illâ al-lâh dengan kaifiyat yang ditentukan dan dzikir khafiy. Proses ini berlaku bagi talqin dzikir dalam berbagai kondisi jamaah. Latar belakang apapun jamaahnya, sendirian atau berjamaah.

\section{Keberhasilan Metode Talqin Dzikir Sebagai Metode Dakwah Jama'ah dan Fardiyyah}

Pada dasarnya, aktivitas dakwah menargetkan terjadinya perubahan, baik individu maupun kelompok, karenanya proses dakwah sendiri pada dasarnya merupakan proses komunikasi sosial yang dilakukan untuk melakukan perubahan. Dakwah dilakukan bukan hanya dalam menyampaikan suatu pesan. Dakwah juga sering dilakukan justru untuk menumbuhkan gairah dan kesenangan, sekaligus mendorong untuk melakukan suatu tindakan (Muhyiddin, 2002). Sebab melalui dakwah inilah akan timbul hubungan dai dan mad'u yang semakin hangat, komunikatif, dan menyenangkan.

Kesenangan dalam berdakwah akan menjadi jembatan persuasi. Salah satu tujuan komunikasi persuasif adalah memengaruhi sikap. Seorang khatib selalu memengaruhi sikap jamaah dengan mengemukakan hal-hal yang menyenangakan. Seorang guru juga memengaruhi sikan murid-muridnya dengan menjanjikan reward yang menggairahkan. Dakwah juga dilakukan untuk membangun hubungan sosial yang baik di antara orang-orang yang sedang terlibat dalam aktivitas dakwah. Hubungan sosial yang baik inilah yang akan mendorong seseorang melakukan tindakan sesuai dengan muatan pesan yang disampaikan.

Sebagai metode dakwah, talqin dzikir dinilai berhasil berhasil dalam semua konteks dakwah jama'ah maupun fardiyyah. Keberhasilan ini ditandai dengan tersentuhnya tiga aspek titik bidik dakwah, baik intelektual, rasional, maupun kinestetikal.

Dari hasil wawancara terungkap beberapa keberhasilan talqin dzikir sebagai metode dakwah yaitu merasakan lebih bisa bersabar, dan selalu siap menghadapi berbagai ujian, adanya ketercerahan pemikiran setelah mengikuti talqin dzikir, terbukanya cara mengingat Allah dengan cara yang tidak sulit, dan mendapatkan perasaan seperti terlahir kembali (Maksum, 2008). Merasa semakin semangat bekerja, semangat beribadah, dan intinya lebih banyak mengubah perilaku buruk, menjadi pelan-pelan semakin baik. Dalam hal ini keberhasilan talqin dzikir sebagai metode dakwah fardiyah juga sebagai dakwah jama'ah.

\section{Implikasi Talqin Dzikir Sebagai Metode Dakwah Jama'ah dan Fardiyyah}

Tasawuf merupakan salah satu cara pandang terhadap ajaran Islam yang melengkapi cara pandang fikih, teologi, dan filsafat. Implikasi talqin dzikir sebagai metode dakwah menjadi positif bagi penembangan dakwah (Kartanegara, 2006). Hal ini ditandai dengan kemampuan talqin dzikir menjawab tiga aspek; efisiensi waktu, efektivitas capaian terhadap target, dan kontinyuitas kebaikan pasca talqin dzikir. Tasawuf positif perlu dikembangkan untuk memberikan alternatif cara hidup keruhanian yang sehat dan progresif, bukan spiritualisme dekaden dan eksesif sebagai mana tampak dalam kecenderungan penganut tasawuf masa kini.

Melihat posisi strategis inilah, talqin dzikir diyakini sebagai salah satu metode yang efektif dalam menyampaikan dakwah. Talqin dzikirr sangat sedikit memerlukan penguasaan teknik ceramah. 
Talqin dalam konteks pengembangan metode dakwah, jawaban beberapa responden dapat dikategorikan sebagai berikut: Ada aspek efisiensi waktu, aspek efektivitas capaian target dakwah, aspek kontinyuitas kebaikan.

\section{SIMPULAN}

Secara konseptual talqin dzikir dapat dibuat menjadi dua penegertian. Pertama, secara formal atau kasat mata, talqin dzikir adalah petunjuk dan penjelasan tentang kaifiyat dzikir jahr dan dzikir kahfiy, yang disampaikan oleh mursyid sebagai pemegang otoitas talqin, atau yang diberi wewenang untuk menyampaikan talqin tersebut atas nama mursyid, yang disebut wakil talqin. Kedua, secara substansial talqin dzikir bermakna menanamkan kalimat talqin lâ ilâha illâ al-lâh, ke dalam ruh peserta talqin oleh guru mursyid. Prosesnya terbagi menjadi tiga tahap. Pertama, tahap persiapan berupa pra kondisi peserta talqin. Kedua, tahap pelaksanaan talqin dzikir. Ketiga, tahap evaluasi talqin dzikir. Keberhasilan Metode Talqin Dzikir Sebagai Metode Dakwah Jama'ah dan Fardiyyah Sebagai metode dakwah, talqin dzikir dinilai berhasil berhasil dalam semua konteks dakwah jama'ah maupun fardiyyah. Keberhasilan ini ditandai dengan tersentuhnya tiga aspek titik bidik dakwah, baik intelektual, rasional, maupun kinestetikal. Implikasi Talqin Dzikir Sebagai Metode Dakwah Jama’ah dan Fardiyyah Metode dakwah talqin dzikir berimplikasi positif bagi penembangan dakwah. Hal ini ditandai dengan kemampuan talqin dzikir menjawab tiga aspek; efisiensi waktu, efektivitas capaian terhadap target, dan kontinyuitas kebaikan pasca talqin dzikir.

\section{DAFTAR PUSTAKA}

Alba, C. (2012). Tasawuf dan Tarekat; Dimensi Esoteris Ajaran Islam. Bandung: PT. Remaja Rosda Karya.

Cucu. (2010). Model Dakwah terhadap Perempuan Perkotaan. Bandung: UIN Sunan Gunung Djati.

Hefni, M. S. dan H. (2006). Metode Dakwah. Jakarta: Rahmat Semesta.

Kartanegara, M. (2006). Menyelami Lubuk Tasawuf. Jakarta: Erlangga.

Kuswarno, E. (2009). Metodologi Penelitian Komunikasi Fenomenologi; Konsepsi, Pedoman, dan Contoh Penelitian. Bandung: Widya Padjadjaran.

Maksum, A. (2008). Pengantar Filsafat; Dari Masa Klasik Hingga Postmodernisme. Ar-Ruz Media: Yogyakarta.

Mubârak, M. S. (2005). Al-Da'wat wa al-Idârat, Fahrasat Maktabat al-Malak Fahd Al-Wathâniyyat. Madinat: Atsnâ al-Nasyr.

Muhyiddin, A. (2002). Metode Pengembangan Dakwah. Bandung: Pustaka Setia.

Sukayat, T. (2009). Quantum Dakwah. Jakarta: Rineka Cipta.

Umar, T. Y. (2004). Islam dan Dakwah. Jakarta: Al-Mawardi Prima. 